\title{
Fine Needle Aspiration Cytology Correlates with Histopathology - A Diagnostic Tool in Children.
}

\author{
Varsha Bhatia ${ }^{1}$, B.N Hiwale ${ }^{2}$ \\ ${ }^{1}$ Assistant Professor, Department of Pathology, Grant Government Medical College, Mumbai, India. \\ ${ }^{2}$ Associate Professor, Department of Pathology, Grant Government Medical College, Mumbai, India
}

\begin{abstract}
Fine Needle Aspiration Cytology (FNAC) in simple words is "aspiration by fine needle". It is the study of cells obtained by puncturing organs of human body with the use of a small-gauge needle. It has become an increasingly popular and widely accepted procedure for evaluating palpable, nonpalpable, superficial, deep masses and can be readily applied for providing diagnosis in pediatric patients. This research aims to study the spectrum of lesions aspirated in pediatric patients and to correlate the cytological diagnosis with the histopathological diagnosis.

Materials \& methods: This is the prospective study which included children aged 0-18 years of either sex with swelling in any part of the body during the years 2008-2010 investigated by FNAC with/without a biopsy. FNAC smears were stained with haematoxylin and eosin $(H \& E)$ and special stains. Histopathological slides were prepared using the paraffin-embedding method and stained with $H \& E$.

Results: A wide spectrum of lesions were aspirated. The total number of aspirates was 495; only $15.75 \%$ were unsatisfactory. Of the $84.24 \%$ satisfactory aspirates, the majority were benign $82.82 \%$.The benign cytological diagnosis revealed lymphadenitis in the majority $60.73 \%$. Of the malignant cases, the maximum were small round cell tumours $42.85 \%$. Histopathological examination was possible in 64 cases and 56 were confirmed on histology. The diagnostic accuracy of FNAC was $87.50 \%$. Its sensitivity, specificity, positive and negative predictive value was $90.32 \%, 100 \%, 100 \%$ and $25.00 \%$ respectively. $p$ value $<0.05$ indicated statistical significance.

Conclusion: FNAC is a simple, safe, rapid, sensitive, specific and an inexpensive bedside method. It provides diagnostic and therapeutic advantages. It helps the surgeon to select, guide and modify surgical treatment. FNAC is recommended as a first line of investigation and a diagnostic modality in children.
\end{abstract}

Keywords: FNAC, Histopathology, Pediatric.

\section{Introduction}

Fine Needle Aspiration Biopsy (FNAB)/ Fine Needle Aspiration Cytology (FNAC) in simple words is "aspiration by fine needle" $[1,2]$. FNAC is a simple, safe, rapid, accurate and an inexpensive bedside method to obtain a tissue specimen for diagnosis of suspicious lesions. In this era of cost conscious medicine, FNAC is a technique which speeds up the process of diagnosis, limits the physical and psychological discomfort to the patient and saves the expenditure of hospitalization. It helps the surgeon to select, guide and modify surgical planning in patients requiring surgery. It is a valuable tool to follow up patients with a history of malignancy and also reduces the necessity to perform excision biopsy in many cases, where the diagnosis is definite, saving the children from surgical complications and thus it can be recommended as a first line of investigation in the diagnosis of swellings in the pediatric age group [3-5]

\section{Materials and Methods}

All the cases of FNAC reported during the period May 2008 to May 2010 in the pediatric age group i.e. $0-18$ years were reviewed. The corresponding histopathological diagnosis in those cases that were subsequently biopsied was also reviewed and a correlation between the two diagnoses was made. Children aged 0-18 years of either sex were included with swelling/s in any part of the body/organ during the years 2008-2010 which was investigated by FNAC with/without a biopsy. FNAC smears were stained with haematoxylin and eosin (H\&E), Papanicolaou, May Grunwald Giemsa and special stains. Histopathological slides were prepared using the paraffin-embedding method and stained with H\&E.

\section{Results}

A wide spectrum of lesions were aspirated. The total number of aspirates was 495 . In this study of pediatric FNACs the age range included was 0-18 years, which was subdivided into four groups: 0-1 year, 1-6 years, 7-12 years and 13-18 years. The aspirates were more in the older age group (13-18 years) $-66.26 \%$. The majority of aspirates were of benign nature $82.82 \%$ and very few were malignant $1.41 \%$. The rest of the aspirates were unsatisfactory $15.75 \%$ (Table 1 ). The youngest patient was 11 months old and the oldest was 18 
years old. The sex distribution of the FNA diagnosis revealed a female preponderance $61.01 \%$ as compared to males $38.98 \%$ were from males (Table 2). A subdivision of the FNA diagnosis according to anatomic site revealed a distinct preponderance of head, neck and face region over all other sites $67.47 \%$. The least number of aspirates were from lower extremity $2.02 \%$. At all anatomic sites, benign diagnoses exceeded malignant cases (Table 3). A subdivision of the FNA diagnosis according to specific organs revealed a distinct preponderance of cases involving the lymph nodes $60.20 \%$. This was followed by breast $13.93 \%$, bone and soft tissue $10.90 \%$. The least number of aspirates were from retroperitoneal structures and male gonad $0.20 \%$ each (Table 4). In all organs, benign diagnosis was found in the majority except for the retroperitoneal structures and male gonad where malignancy was the sole finding. In breast, thyroid, salivary gland, skin and sub cutis (epidermal/sebaceous/dermoid cysts) all the aspirates were benign. When the benign cytological diagnosis were subtyped, the maximum number of aspirates were from lymph nodes 60.73\%; of which majority were inflammatory $57.42 \%$. In the inflammatory category, the majority were specific infections i.e. tuberculous $89.51 \%$ (Fig 1a,b,c,d, Fig 2a \& 2b). The lymphadenitis category was followed by fibroadenoma of the breast (Fig 3a,3b,4a,4b) (Table 5). In this study, AFB smears were studied in all $128 \mathrm{~TB}$ cases. The smears were positive in $45.31 \%$ cases and negative in $54.68 \%$ cases (Fig 5). The other systemic diseases associated with lymphadenopathy were pulmonary Koch's $10 \%$ followed by HIV $2 \%$ cases (Table 6). There were only 07 aspirates which were positive for malignancy. Out of these the maximum number were malignant small round cell tumour $42.85 \%$ (Fig 6) followed by lymphomas $28.57 \%$ (Fig 7) which could not be sub-typed on FNAC (Table 7). In this study, 64 cases were examined histopathologically and correlation between the FNA smear diagnosis and histopathological diagnosis was done with the help of statistical analysis and the sensitivity, specificity, predictive value and test of significance applied for the test. Amongst the 64 cases diagnosed on cytology, 56 cases were confirmed on histology. Diagnosis changed on histopathology in 06 cases and 02 cases showed normal histology (Table 8). In this study, sensitivity of FNA was found to be $90.32 \%$ and the specificity was $100 \%$. On referring to $\chi^{2}$ table, with degree of freedom, $\mathrm{p}<0.0066$ was statistically significant. According to Fisher's test, $\mathrm{p}$ value equalled 0.0139 ( $\mathrm{p}<0.05)$, indicating the test to be statistically significant. The test is more significant and is to be used for diagnostic purposes with significant diagnostic accuracy value. The predicative power of the FNA test in the pediatric population is very high (i.e. PPV $=100 \%$ ) and the test is statistically significant $(\mathrm{p}<0.05)$. Hence this study proves that FNA is a very important diagnostic modality in the pediatric age group.

\section{Discussion}

Fine needle aspiration biopsy is a very sensitive, specific and an accurate method for evaluating both palpable and non-palpable, superficial and deep masses in pediatric patients[1,3,4]. It provides diagnostic and therapeutic advantages in cases of superficially accessible organs and tissues e.g. lymph nodes, breast, thyroid, skin and also in cases of deep solid enlarged intra-abdominal lymph nodes, space occupying lesions of kidney, liver, pancreas and a few cystic masses [1]. FNA is an operator dependent procedure, which for optimal results requires a good co-operation between the clinician and the pathologist. In case of lymph node malignancy such as Non-Hodgkin's lymphoma, FNAC provides a quick diagnosis; thus surgical biopsy and inappropriate procedures can be avoided. FNA of the testis enables us to distinguish between inflammatory and neoplastic lesions pre-operatively [6]. While the type of malignancy can be diagnosed, FNA does not give information about the architecture of the tumour. In order to improve resectability, patients receive pre-operative chemotherapy such as in Wilm's tumour and rhabdomyosarcoma. Pre-treatment has been shown to downgrade the atypia seen in some Wilm's tumours which could result in under treatment if complete histology is not obtained prior to treatment. This difference in information obtained from FNA biopsy and open biopsy and how this subsequently affects treatment must be weighed against the risk of gross tumour spillage, infection and delay in therapy with open biopsy. FNA should be utilized for the diagnosis of recurrent lesions; tumours that do not appear readily resectable; in an obvious disseminated disease to allow for early initiation of therapy [7].

In our study, as in Table 1, we have included the age range of 0-18 years and further subdivided this age range into four categories Our findings were similar to the series of Taylor et al [8], Silverman et al [9] and Smith et al [7], they took 18 years as age range. In our study, the majority of aspirates were benign $83 \%$ and revealed a female preponderance. This finding correlates well with the findings of Wakely et al [10] who also found the maximum number of cases $(62.5 \%)$ in the benign category with a female preponderance. The number of aspirates according to anatomic site, revealed a distinct preponderance of head, neck and face $67 \%$ over all other sites. Our findings correlate with Howell et al [4] who also found the maximum number of aspirates in head, neck and face region $(64.81 \%)$. A subdivision of the FNA diagnosis according to the organ involved, revealed a distinct preponderance of lymph node aspirates $60 \%$ over all other organs. Our findings correlate well with the studies of Wakely et al [10], Cohen et al [3], Howell et al [4], Mobley et al [11]. They also found the maximum number of benign aspirates from lymph nodes and also benign aspirates in all other organs. We subtyped the benign cytological diagnosis and lymphadenitis $(60.73 \%)$ was the diagnosis in the majority of the aspirates. Our 
Fine Needle Aspiration Cytology Correlates With Histopathology - A Diagnostic Tool In Children.

findings correlate well with studies of Wakely et al [10] (44.28\%), Howell et al [4] (62.96\%), Mobley et al [11] (78.57\%) where the majority of cases were of lymphadenitis. In our study, in the lymphadenitis category, the majority of the aspirates were inflammatory (57.42\%) followed by reactive lymphadenitis (42.57\%). These findings correlate with those of Howell et al [4]. Amongst the malignancies, we found maximum number of cases of malignant small round cell tumour $(42.85 \%)$ which could not be sub-typed on FNAC. Our findings correlate with Taylor et al [8] (73.68\%), Cohen et al [3] (66.66\%), Smith et al [7] (38.40\%) they also found maximum number of cases of malignant small round cell tumour.

We examined 64 cases on histopathology, and correlation between the FNA smear diagnosis and histopathological diagnosis was done with help of statistical analysis. Of the 64 FNACs, 56 were confirmed on histopathology and the diagnosis changed with histopathology in 06 cases. So the diagnostic accuracy was $87.50 \%$ which indicates a good correlation. Other authors Jereb et al [12] (93\%), Taylor et al [13] (89\%) have also found a good correlation. We found the sensitivity of the FNAC procedure to be $90.32 \%$ while its specificity was $100 \%$. The positive predictive value (PPV) was $100 \%$ and the negative predictive value was $25.00 \%$; false positive rate being $9.67 \%$ and false negative rate was $0 \%$. The $\mathrm{p}$ value $<0.05$ indicated that the test was very significant. The sensitivity and specificity reported by other authors ranged from $76 \%-97 \%$ and 95\% - 100\% respectively. The positive predictive value (PPV) reported by other authors ranged between $89.4 \%$ - $100 \%$ while the negative predictive value was $94.7 \%$ reported by Silverman et al [9]. Other studies have shown a false positive rate in the range of $2-0 \%$ and a false negative rate in the range of $7-0 \%$. Our findings match with those found in other studies, except for a negative predictive value which is much lower at $25 \%$ and a false positive rate of $9.67 \%$

\section{Conclusion}

"Diagnosis by aspiration is as reliable as the combined intelligence of the clinician and the pathologist make it". This was emphasized about seventy years ago by Stewart [14] FNAC may be performed by a clinician, pathologist or radiologist as an outpatient procedure. So along with other advantages it brings a new dimension of cooperation between the medical specialist, cytopathologist and radiologist in this era of emphasis on ambulatory care [1].

Table 1: Age range and FNA diagnosis

\begin{tabular}{|l|l|l|l|l|}
\hline Age (years) & Benign & Malignant & Inadequate & Total \\
\hline $0-1$ & 02 & 00 & 01 & $\begin{array}{l}03 \\
(0.60 \%)\end{array}$ \\
\hline $1-6$ & 45 & 03 & 20 & $\begin{array}{l}68 \\
(13.73 \%)\end{array}$ \\
\hline $7-12$ & 86 & 00 & 10 & $\begin{array}{l}96 \\
(19.39 \%)\end{array}$ \\
\hline $13-18$ & 277 & 04 & 47 & $\begin{array}{l}328 \\
(66.26 \%)\end{array}$ \\
\hline Total & $\begin{array}{l}410 \\
(82.82 \%)\end{array}$ & $\begin{array}{l}07 \\
(1.41 \%)\end{array}$ & $\begin{array}{l}\mathbf{7 9 5}(15.75 \%) \\
(100 \%)\end{array}$ \\
\hline
\end{tabular}

Mean age - 9.5 years

2: Sex distribution and FNA diagnosis

\begin{tabular}{|l|l|l|l|l|}
\hline Sex & Benign & Malignant & Unsatisfactory & Total \\
\hline Male & 156 & 04 & 33 & $193(38.98 \%)$ \\
\hline Female & 254 & 03 & 45 & $302(61.01 \%)$ \\
\hline Total & $410(82.82 \%)$ & $\begin{array}{l}07 \\
(1.41 \%)\end{array}$ & $\begin{array}{l}78 \\
(15.75 \%)\end{array}$ & $495(100 \%)$ \\
\hline
\end{tabular}


Fine Needle Aspiration Cytology Correlates With Histopathology - A Diagnostic Tool In Children.

Table 3: Anatomic sites and FNA diagnosis

\begin{tabular}{|l|l|l|l|l|}
\hline Site & Benign & Malignant & Inadequate & Total \\
\hline Head, Neck and Face & 280 & 03 & 51 & $334(67.47 \%)$ \\
\hline Chest and Back & 89 & 00 & 18 & $107(21.61 \%)$ \\
\hline Abdomen & 12 & 03 & 05 & $20(4.04 \%)$ \\
\hline $\begin{array}{l}\text { Upper } \\
\text { Extremity }\end{array}$ & 20 & 01 & 03 & $24(4.84 \%)$ \\
\hline $\begin{array}{l}\text { Lower } \\
\text { Extremity }\end{array}$ & 09 & 00 & 01 & $10(2.02 \%)$ \\
\hline \begin{tabular}{l} 
TOTAL \\
\hline
\end{tabular} & 410 & 07 & 78 & $495(100 \%)$ \\
\hline
\end{tabular}

Table 4: Specific organs and their FNA diagnosis

\begin{tabular}{|l|l|l|l|l|}
\hline Organ & Benign & Malignant & Inadequate & Total \\
\hline Eye and Adnexae & 00 & 01 & 01 & $02(0.40 \%)$ \\
\hline Skin and Subcutis & 24 & 00 & 02 & $26(5.25 \%)$ \\
\hline Salivary Gland & 04 & 00 & 01 & $05(1.01 \%)$ \\
\hline Thyroid & 29 & 00 & 10 & $39(7.87 \%)$ \\
\hline Breast & 63 & 00 & 06 & $69(13.93 \%)$ \\
\hline Lymph Nodes & 249 & 02 & 47 & $298(60.20 \%)$ \\
\hline Bone and Soft Tissue & 41 & 02 & 11 & $54(10.90 \%)$ \\
\hline $\begin{array}{l}\text { Retroperitoneal } \\
\text { Structures }\end{array}$ & 00 & 01 & & $01(0.20 \%)$ \\
\hline Male Gonad & 00 & 01 & 00 & $01(0.20 \%)$ \\
\hline \begin{tabular}{l} 
TOTAL \\
\hline
\end{tabular} & 410 & 07 & 78 & $495(100 \%)$ \\
\hline
\end{tabular}

Table 5: Benign Cytologic Diagnosis

\begin{tabular}{|c|c|}
\hline FNA DIAGNOSIS & NO.OF ASPIRATES \\
\hline $\begin{array}{cc}\text { Inflammatory lesions } & \text { Tuberculous } \mathrm{LN}^{*}=128(31.21 \%) \\
\text { Suppurative } \mathrm{LN}^{*}=15(3.65 \%)\end{array}$ & $143(34.87 \%)$ \\
\hline Reactive Lymphadenitis & $106(25.85 \%)$ \\
\hline Fibroadenoma of breast & $57(13.90 \%)$ \\
\hline Cysts** & $39(9.51 \%)$ \\
\hline Colloid Goitre & $25(6.09 \%)$ \\
\hline Abscess $* * *$ & $14(3.41 \%)$ \\
\hline Lipoma & $07(1.70 \%)$ \\
\hline Lymphocytic Thyroiditis & $04(0.97 \%)$ \\
\hline Fibrocystic disease of breast & $03(0.73 \%)$ \\
\hline Gynecomastia & $03(0.73 \%)$ \\
\hline Pleomorphic Adenoma & $03(0.73 \%)$ \\
\hline Benign Spindle Cell tumour & $03(0.73 \%)$ \\
\hline Fibroma & $02(0.48 \%)$ \\
\hline Sialadenitis & $01(0.24 \%)$ \\
\hline TOTAL & $410(100 \%)$ \\
\hline
\end{tabular}

*Lymph node **Epidermal, Thyroglossal, Ganglion Cyst ***Breast, shoulder, thigh. 
Fine Needle Aspiration Cytology Correlates With Histopathology - A Diagnostic Tool In Children.

Table 6: Cytological diagnosis of Lymphadenopathy

\begin{tabular}{|c|c|}
\hline DIAGNOSIS & NO.OF ASPIRATES \\
\hline Reactive Lymphadenitis & $106(35.57 \%)$ \\
\hline \begin{tabular}{lc} 
Inflammatory & Tuberculous lymphadenitis \\
lymphadenitis & $128(42.95 \%)$ \\
Suppurative lymphadenitis \\
\multicolumn{2}{c}{$15(5.03 \%)$}
\end{tabular} & $143(47.98 \%)$ \\
\hline Malignancy (Non-Hodgkin's Lymphoma) & $02(0.67 \%)$ \\
\hline Inadequate on repeated $\mathrm{FNA}$ & $47(15.77 \%)$ \\
\hline TOTAL & $298(100 \%)$ \\
\hline
\end{tabular}

Table 7: Malignant Cytological Diagnosis

\begin{tabular}{|l|l|}
\hline DIAGNOSIS & NO. OF ASPIRATES \\
\hline Malignant Small Round Cell tumour & $03(42.85 \%)$ \\
\hline Lymphoma & $02(28.57 \%)$ \\
\hline Malignant Spindle Cell tumour & $01(14.28 \%)$ \\
\hline Germ cell tumour & $01(14.28 \%)$ \\
\hline TOTAL & $07(100 \%)$ \\
\hline
\end{tabular}

Table 8:Correlation between cytological and histopathological diagnosis:

\begin{tabular}{|c|c|c|c|}
\hline FNA Cytology & & Histopathology & \\
\hline Diagnosis & $\begin{array}{l}\text { No. of } \\
\text { Aspirates }\end{array}$ & Diagnosis & No. of cases \\
\hline TB Lymphadenitis & 01 & $\begin{array}{ll}\text { Chronic } & \text { non-specific } \\
\text { lymphadenitis } & \\
\end{array}$ & 01 \\
\hline \multirow[t]{2}{*}{ Fibroadenoma } & \multirow[t]{2}{*}{34} & Fibroadenoma & 32 \\
\hline & & Fibrocystic disease & 02 \\
\hline Fibrocystic disease & 01 & Fibroadenoma & 01 \\
\hline Gynaecomastia & $\mathbf{0 2}$ & Gynaecomastia & $\mathbf{0 2}$ \\
\hline \multirow[t]{3}{*}{ Cystic lesion } & \multirow[t]{3}{*}{13} & $\begin{array}{l}\text { Epidermal/ Sebaceous / Dermoid } \\
\text { cyst }\end{array}$ & 09 \\
\hline & & Ganglion cyst & $\mathbf{0 3}$ \\
\hline & & Thyroglossal cyst & 01 \\
\hline \multirow[t]{3}{*}{ Colloid goitre } & \multirow[t]{3}{*}{$\mathbf{0 3}$} & Colloid Goitre & 01 \\
\hline & & Follicular Adenoma & 01 \\
\hline & & Lymphocytic thyroiditis & 01 \\
\hline Lipoma & $\mathbf{0 2}$ & Lipoma & $\mathbf{0 2}$ \\
\hline \multirow{5}{*}{$\begin{array}{l}\text { Inadequate smear on } \\
\text { repeated FNA }\end{array}$} & \multirow[t]{5}{*}{06} & Reactive Lymphadenitis & 01 \\
\hline & & Sebaceous cyst & 01 \\
\hline & & Non-Hodgkin's lymphoma & 01 \\
\hline & & Neurofibroma & 01 \\
\hline & & Normal histology & $\mathbf{0 2}$ \\
\hline $\begin{array}{l}\text { Malignant Small } \\
\text { Round Cell Tumour }\end{array}$ & 01 & Retinoblastoma & 01 \\
\hline $\begin{array}{ll}\text { Malignant } & \text { Spindle } \\
\text { Cell Tumour } & \\
\end{array}$ & 01 & Synovial Sarcoma & 01 \\
\hline Total & 64 & Total & 64 \\
\hline
\end{tabular}

\section{References}

[1]. Mahmud Q, Mason AU, Siddique N. Percutaneous FNA biopsy with open lymph node biopsy. Professional Med J Mar 2007;14(1):21-31.

[2]. Diamantis A, Magiorkinis E, Koutselini. Fine-needle aspiration (FNA) biopsy: historical aspects. Folia Histochem Cytobiol 2009;47(2):191-7.

[3]. Cohen MB, Bottles K, Ablin AR, Miller TR. The use of fine-needle aspiration biopsy in children. West J Med 1989 Jun;150:665-7.

[4]. Howell LP, Russell LA, Howard PH, Teplitz RL. Fine needle aspiration biopsy of superficial masses in children. West J Med 1991 Jul;155:33-8. 
Fine Needle Aspiration Cytology Correlates With Histopathology - A Diagnostic Tool In Children.

[5]. Jain M, Majumdar DD, Agarwal K, Bais AS, Choudhary M. FNAC as a diagnostic tool in pediatric head and neck lesions. Indian Pediatr 1999 Sep;36:921-3.

[6]. Lever JV, Trott PA, Webb AJ. Fine needle aspiration cytology. J Clin Pathol 1985;38:1-11.

[7]. Smith MB, Katz R, Black CT, Cangir A, Andrassy RJ. A rational approach to the use of fine needle aspiration biopsy in the evaluation of primary and recurrent neoplasm in children. J Pediatr Surg 1993 Oct;28:1245-7.

[8]. Taylor SR, Nunez C. Fine-needle aspiration biopsy in a pediatric population Report of 64 consecutive cases. Cancer 1984 Oct;54 (7):1449-53.

[9]. Silverman JF, Gurley AM, Holbrook CT, Joshi VV. Pediatric fine-needle aspiration biopsy. Am J Clin Pathol 1991 May;95(5):6539.

[10]. Wakely PE Jr, Kardos TF, Frable WJ. Application of fine needle aspiration biopsy to pediatrics. Hum Pathol 1988 Dec;19(12):1383-6.

[11]. Mobley DL, Wakely PE Jr, Frable MA. Fine needle aspiration biopsy: Application to pediatric head and neck masses. Laryngoscope 1991 May;101:469-72.

[12]. Jereb B, Us-Krasovec M, Jereb M. Thin needle biopsy of solid tumours in children. Med Pediatr Oncol 1978;4(3):213-20.

[13]. Taylor SR, Nunez C. Fine-needle aspiration biopsy in a pediatric population Report of 64 consecutive cases. Cancer 1984 Oct;54(7):1449-53.

[14]. Stewart FW. The diagnosis of tumours by aspiration. Am J Pathol 1933;9:810-5.

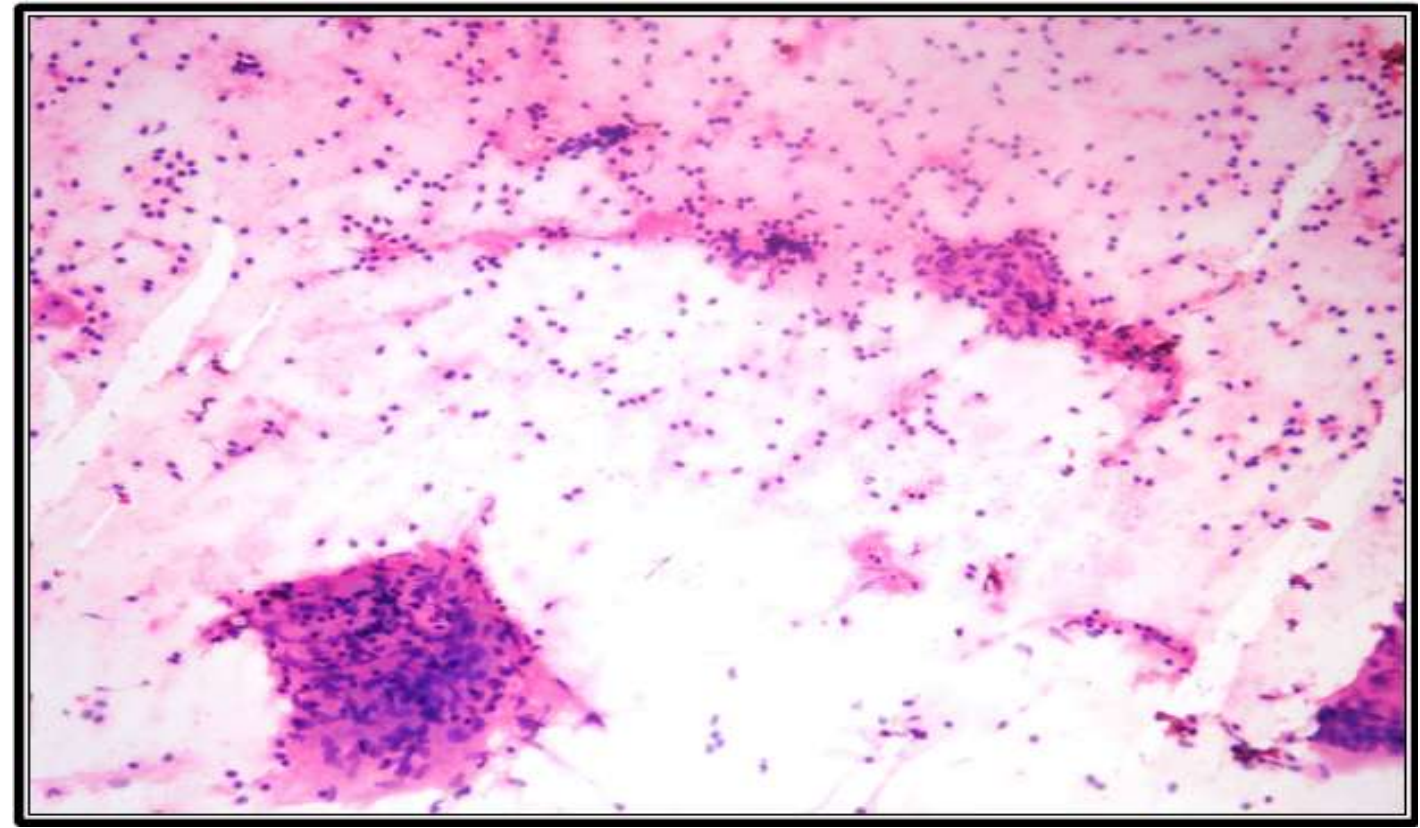

Fig 1a. Microphotograph of FNA smears from tuberculous lymph node showing clusters of epithelioid cell granulomas, lymphocytes. (H\&E 100x)

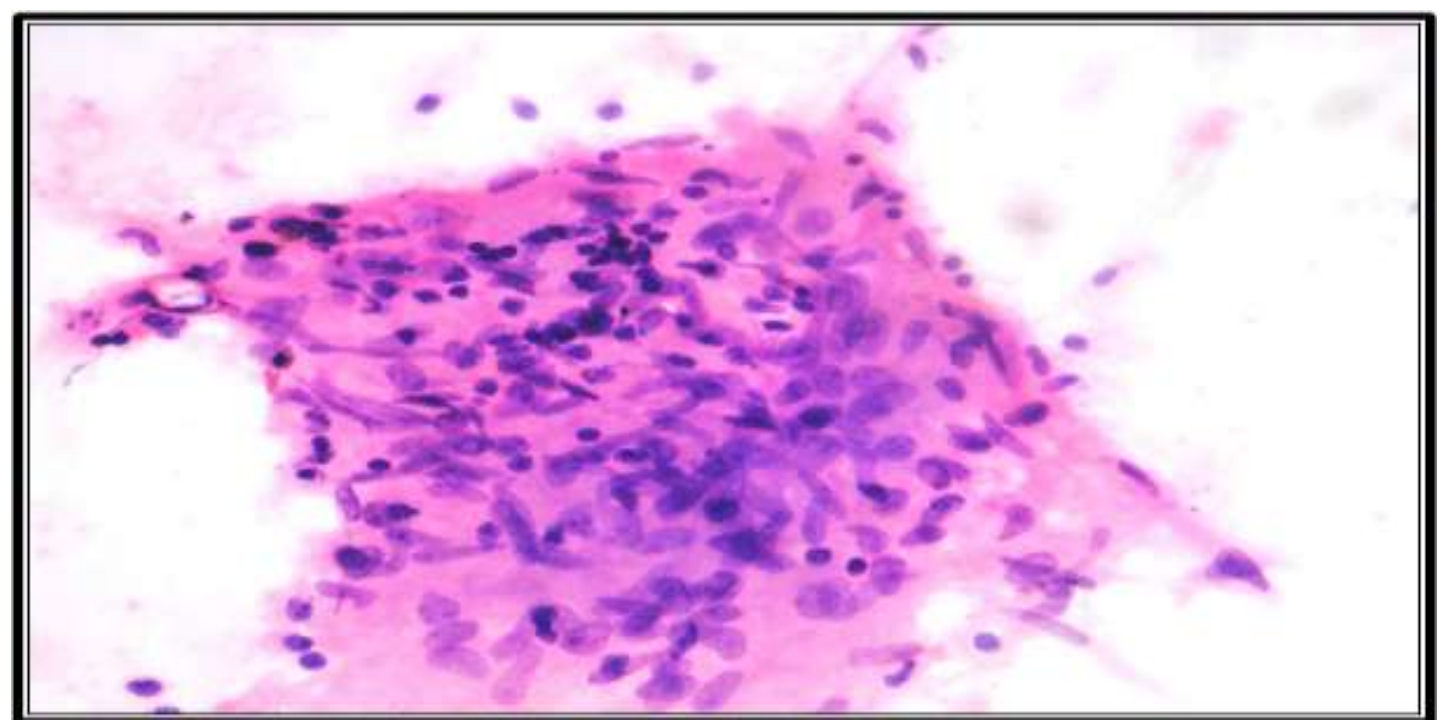

Fig.1b Microphotograph of FNA smears from tuberculous lymph node showing cluster of epithelioid Cells forming granuloma having elongated nuclei and abundant ill defined cytoplasm, lymphocytes. (H\&E 400X) 


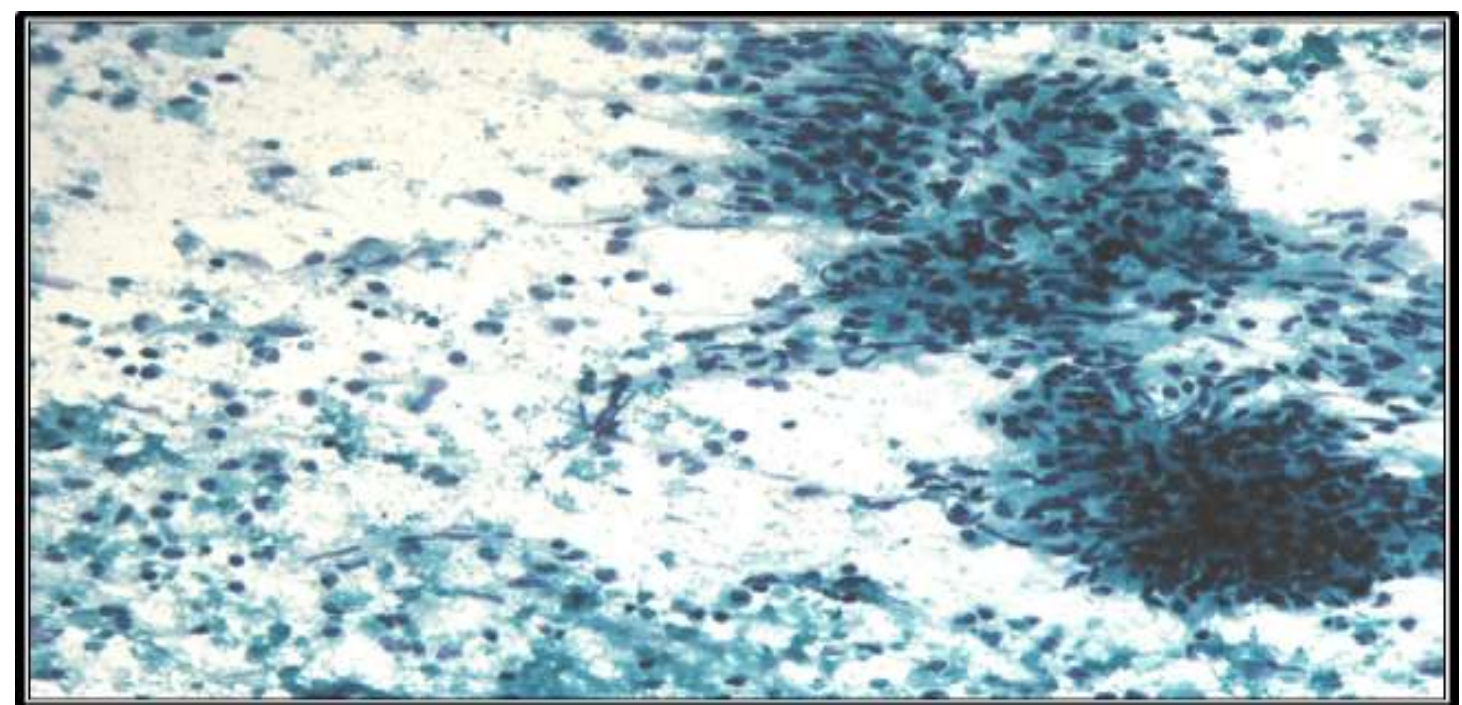

Fig 1c. Microphotograph of FNA smears from tuberculous lymph node showing clusters of Epithelioid cell granulomas, lymphocytes and caseous necrosis. (PAP 100X)

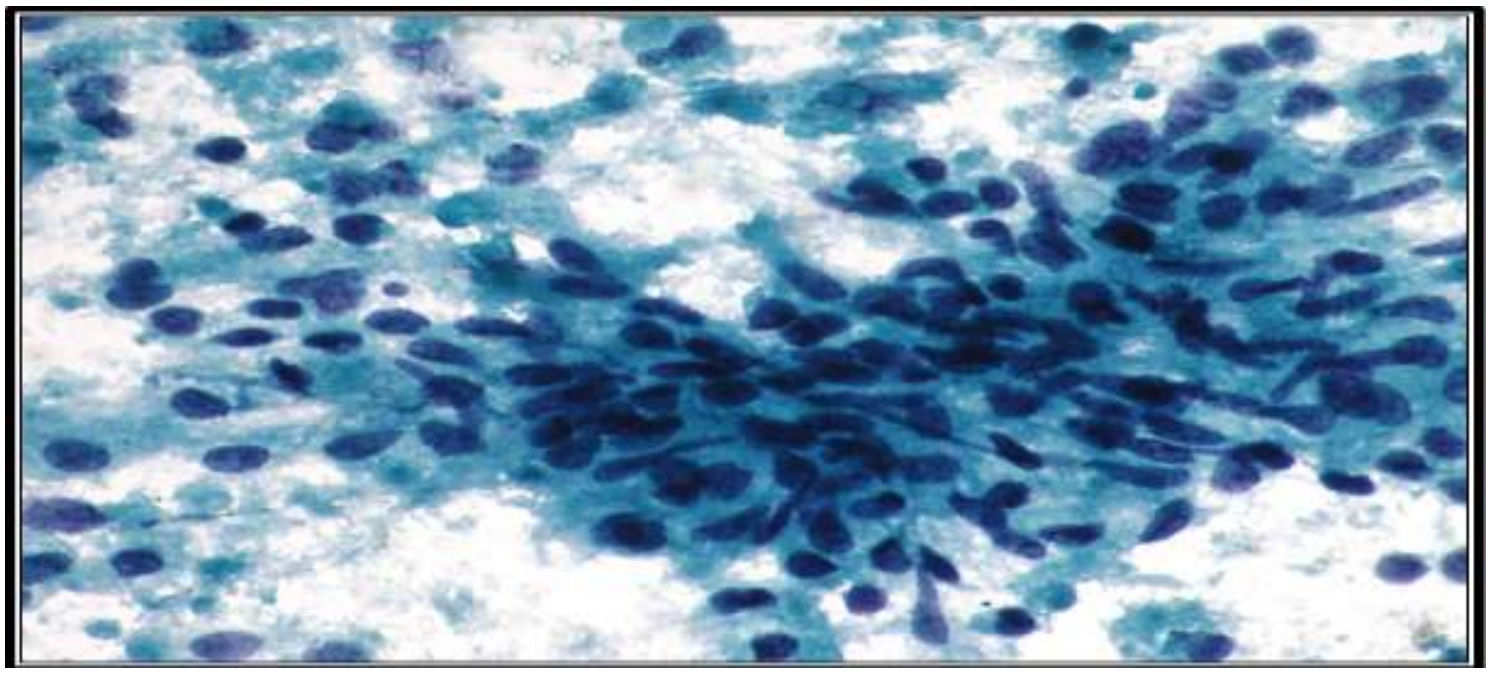

Fig 1d. Microphotograph of FNA smears from tuberculous lymph node showing cluster of epithelioid cells forming granuloma having elongated nuclei and abundant ill defined cytoplasm, lymphocytes and caseous necrosis. (PAP 400X)

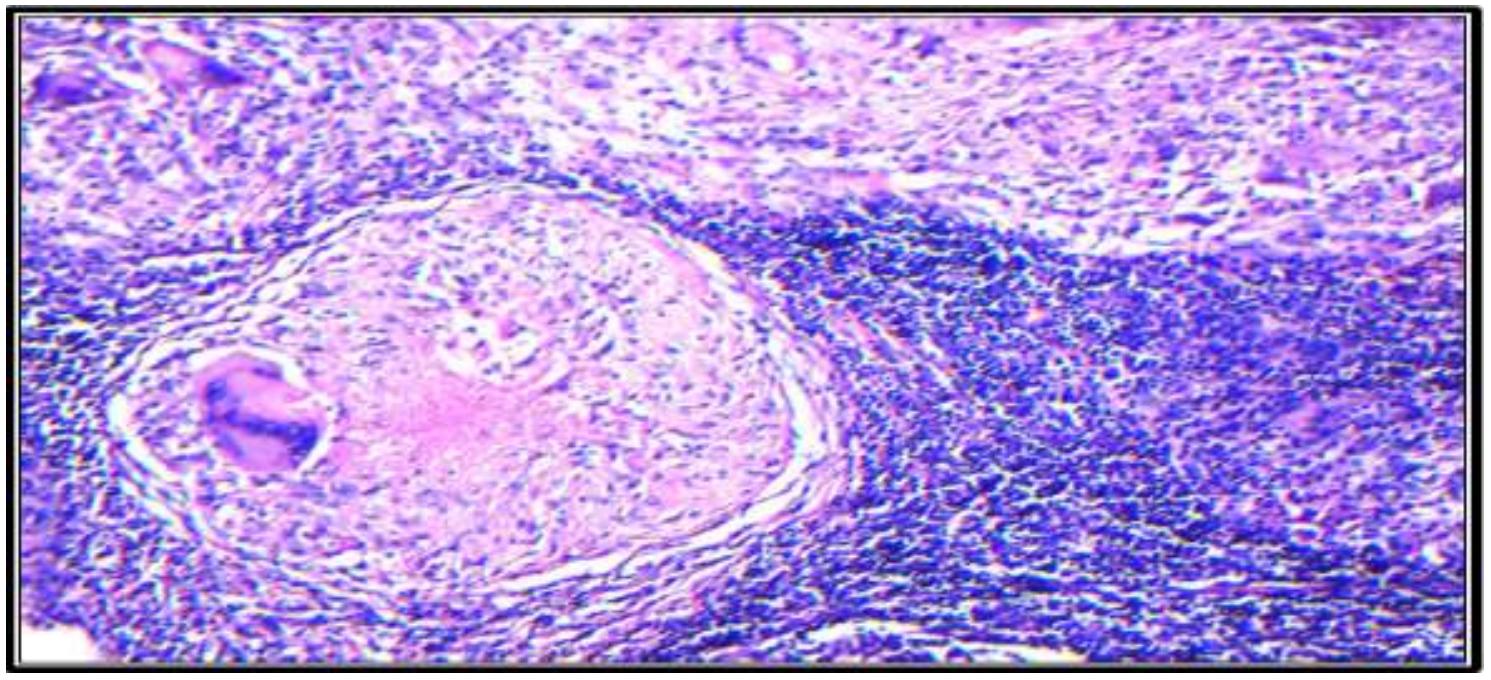

Fig 2a. Histologic section from a tuberculous lymph node showing well formed epithelioid cell granulomas, giant cells, caseous necrosis and lymphocytes. (H\&E 100X) 


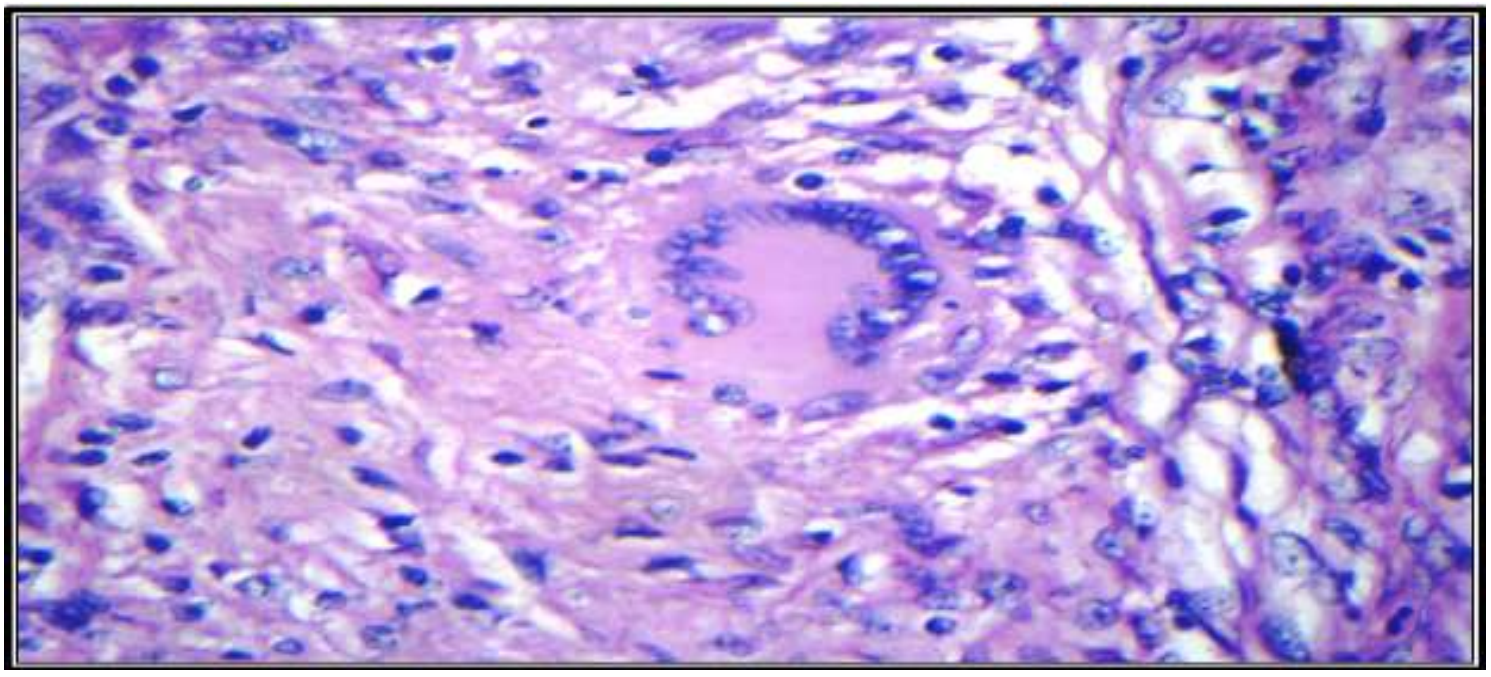

Fig 2b. Histologic section from a tuberculous lymph node showing epithelioid cells, Langhan's giant cell and lymphocytes. (H\&E 400X)

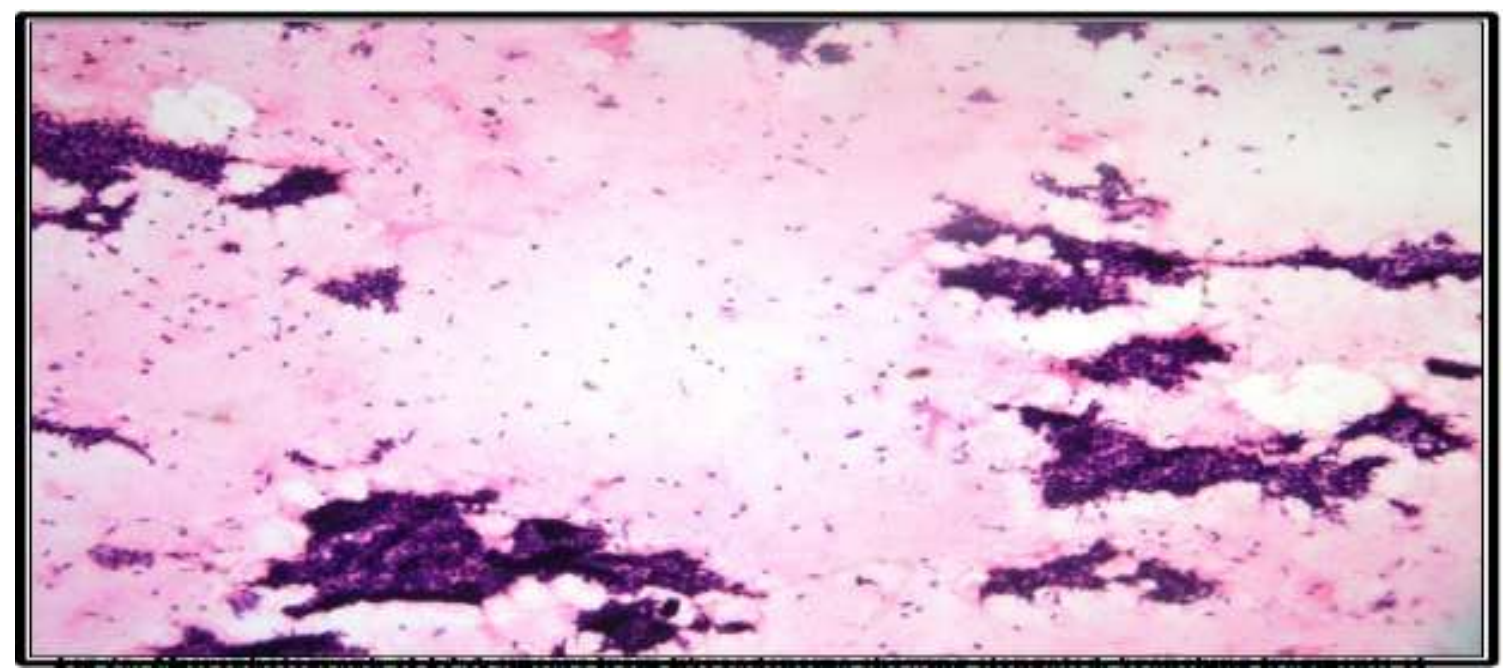

Fig 3a. Microphotograph of FNA smears from fibroadenoma showing elongated, branching fragments of ductal epithelium , numerous single bare bipolar nuclei in the background of Fibromyxoid stroma. (H\&E 100X)

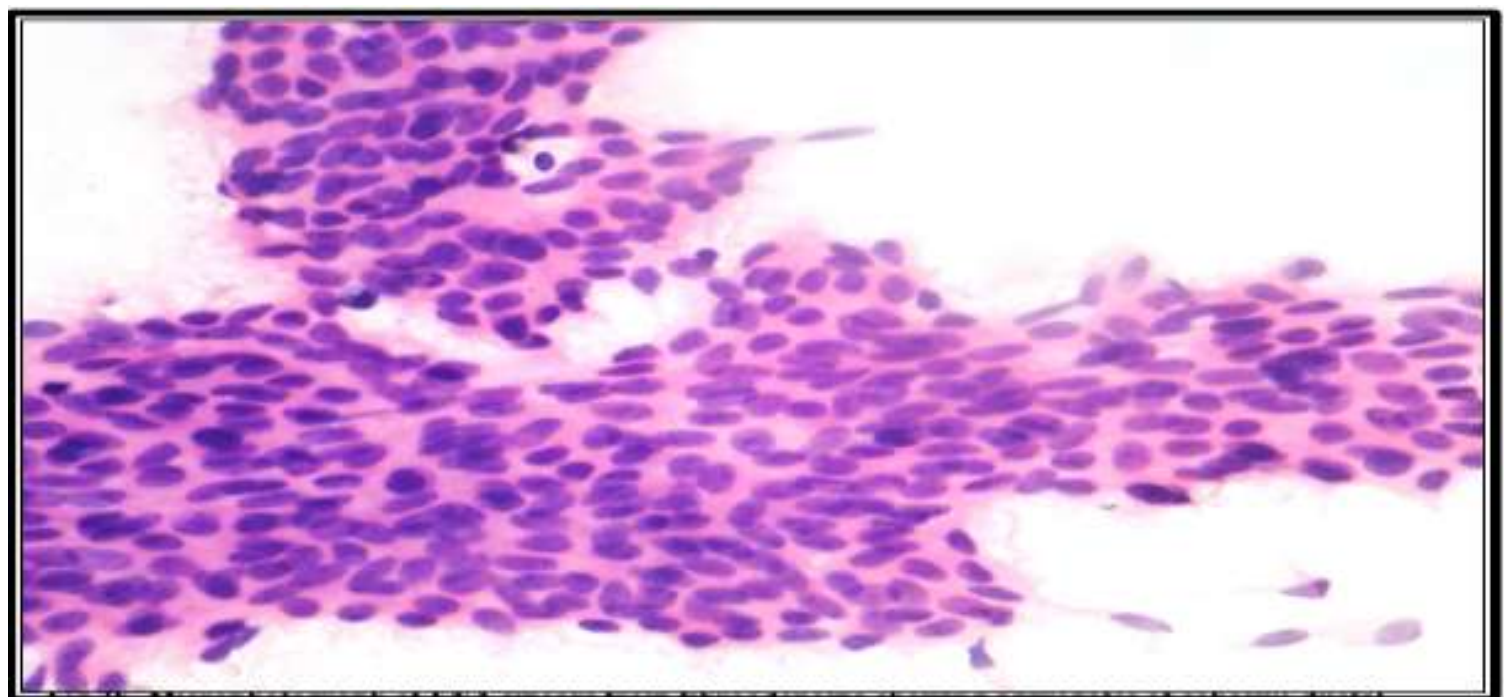

Fig 3b. Microphotograph of FNA smears from fibroadenoma showing aggregates of cohesive ductal epithelial cells , few bare bipolar nuclei. (H\&E 400X) 


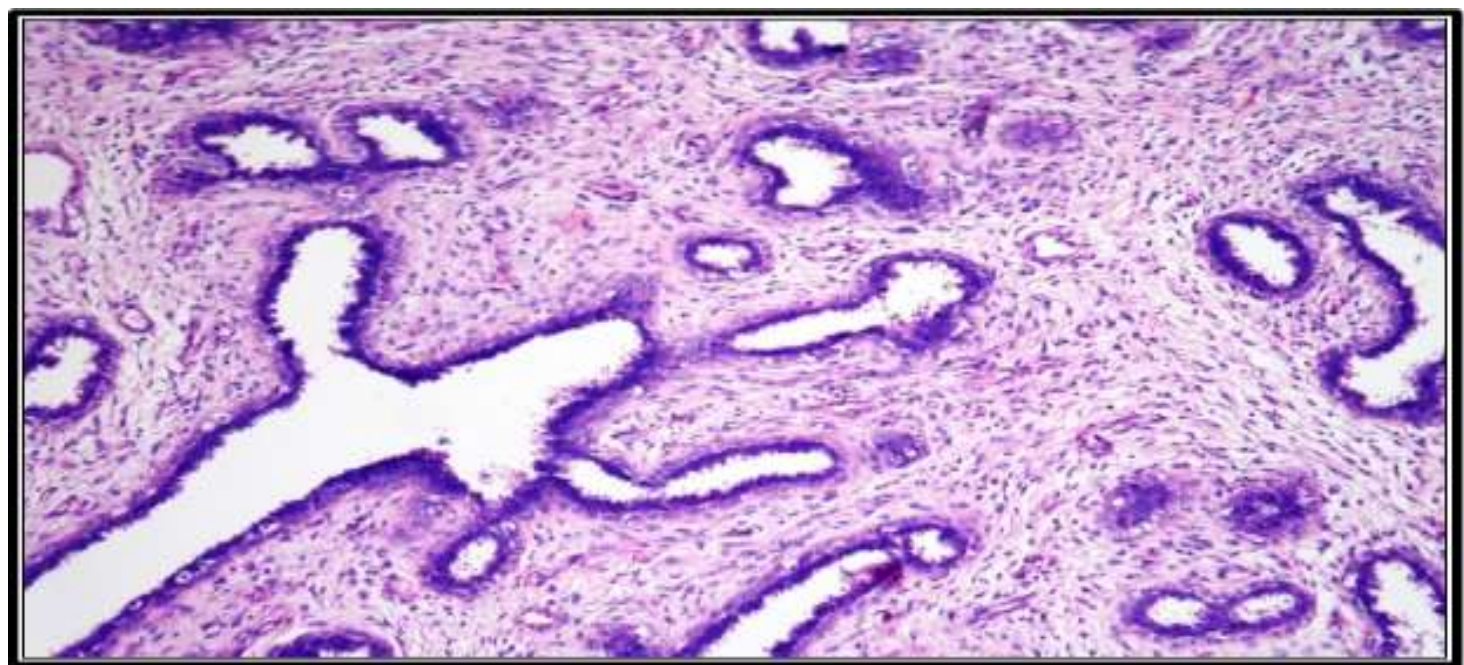

Fig 4a.Histologic section from fibroadenoma showing proliferation of glandular and stromal elements. (H\&E 100X)

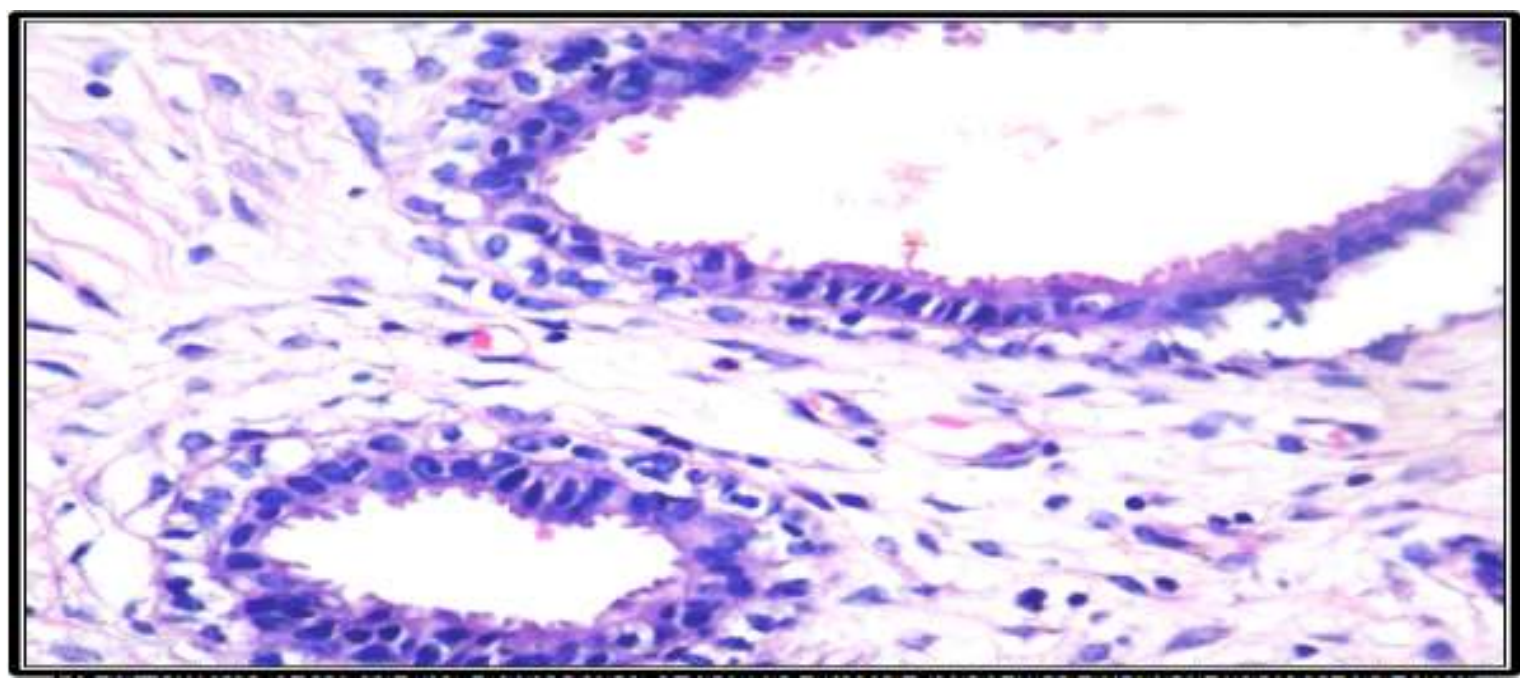

Fig 4b. Histologic section from fibroadenoma showing dilated glands lined by inner cuboidal and outer myoepithelial layer and the stroma is fibrocollagenous. (H\&E 400X)

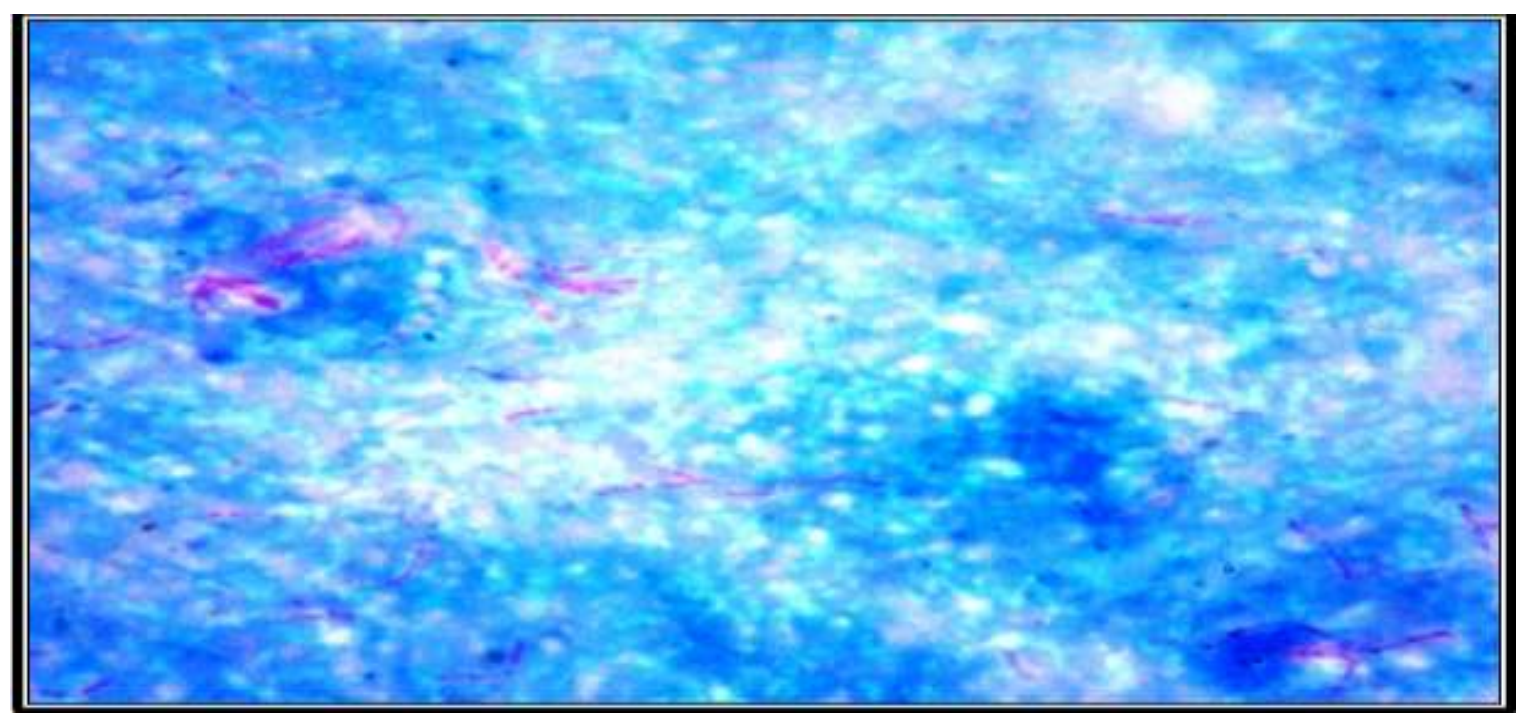

Fig 5. Microphotograph of FNA smears from tuberculous lymphnode showing acid fast bacilli. (Ziehl Neelsen stain under oil immersion). 


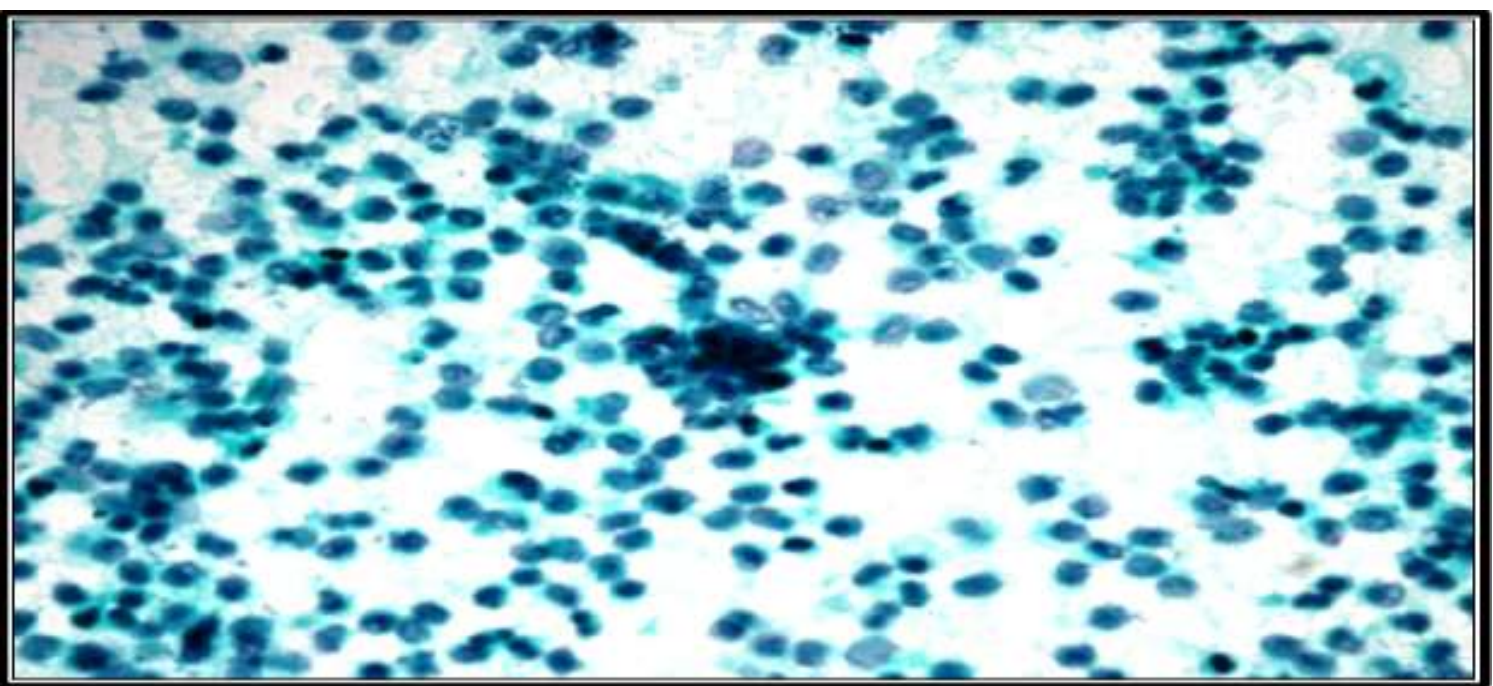

Figure 6 a. Microphotograph of FNA smears from eyeball tumour showing malignant small round tumour cells with hyperchromatic nuclei and scant cytoplasm, occasional rosette formation. (PAP 100X)

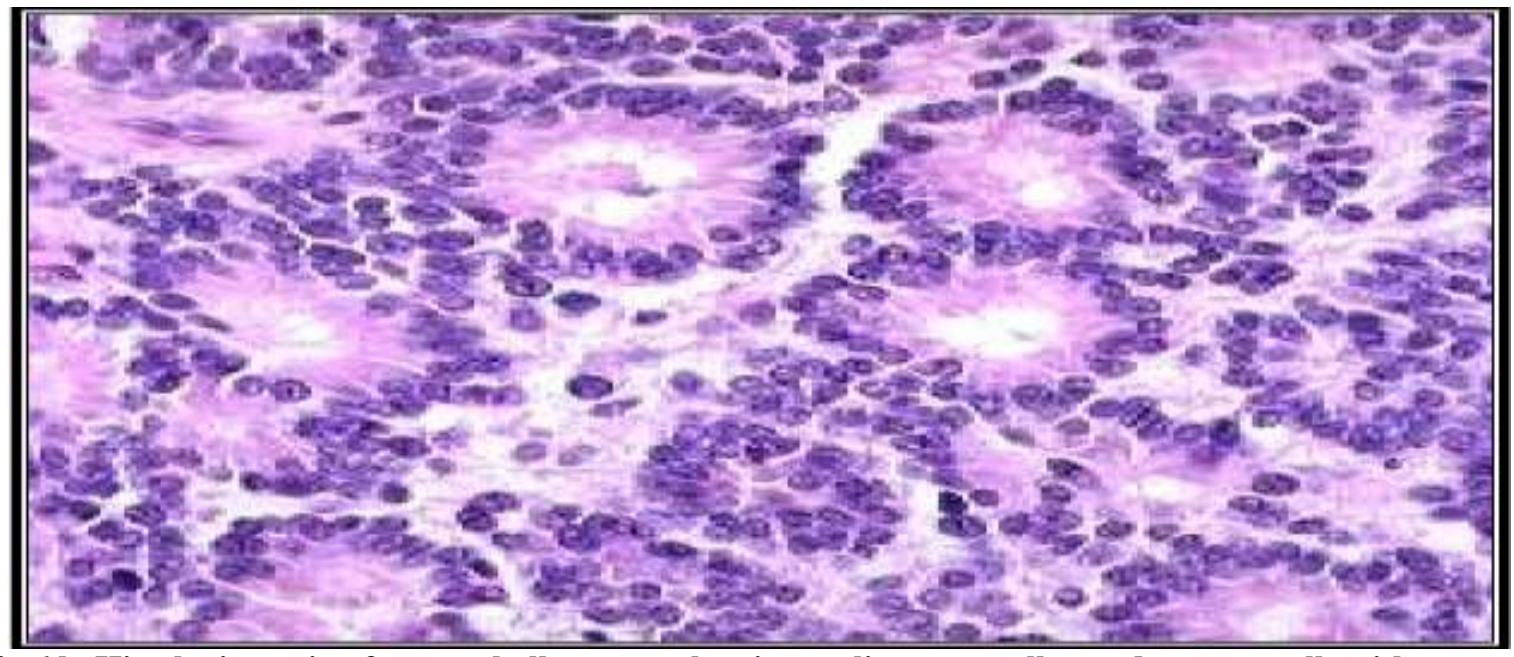

Fig 6 b. Histologic section from eyeball tumour showing malignant small round tumour cells with hyperchromatic nuclei and scant cytoplasm and rosette formation. (H\&E 100X)

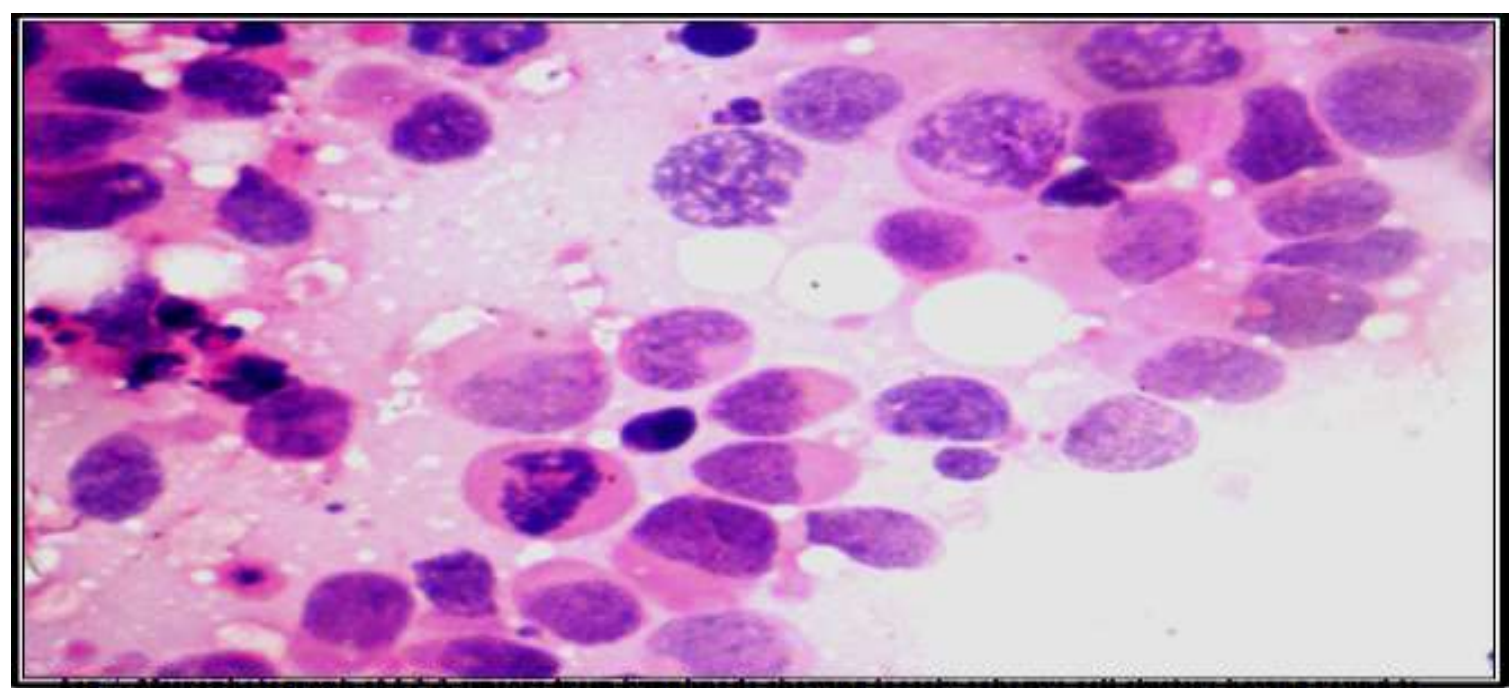

Fig 7. Microphotograph of FNA smears from lymphnode showing loosely cohesive cell clusters having round to oval, central to eccentric nuclei, irregular nuclear margins, coarse chromatin and moderate eosinophilic cytoplasm with brisk mitotic activity. (H\&E 400X) 